\title{
REPRESENTATION AND DIGITALIZATION OF STONE THEATRES IN EASTERN SICILY: THE PALAZZOLO ACREIDE THEATER
}

\author{
G. Di Gregorio
}

Universita' degli Studi di Catania, Italy - giuseppe.digregorio@dau.unict.it

KEY WORDS: Cuturale Heritage, Photogrammetry, FSM, Laser scanner 3D, Drawing

\begin{abstract}
:
The ancient theatres in Sicily, in southern Italy and along the countries facing the Mediterranean Sea basin, constitute a reality of incomparable cultural value. Regarding the research on the ancient theatres of eastern Sicily, few studies have been recently dealt with different methodologies. In the last years some practices have been done using 3D laser scanners for the theatres of Syracuse, Taormina and Morgantina, as well as the Syracuse amphitheatre and Taormina Odeon, just obtaining very interesting results. Lately the theatre of Palazzolo Acreide (Syracuse) has been studied, with Structure From Motion (SFM) and Dense Matching methodologies. From these experience, conclusions could be drawn on the quality and reliability of the elaborations realised with the SFM methodologies. We really know that these systems are today representing one of the fastest growing areas of examination, on which several software houses are investing. The study was chosen both for the small size of the building, and for the particular geometric conditions typical of the architecture of ancient theatres. This because their three-dimensional trend varies continually in the three variables X, Y, Z. The purpose of the work was to check whether the latest releases of these systems of survey allow today more than yesterday, a rapid digitalization and representation of the enormous archaeological cultural heritage. Various software were used, to verify the practicality and operation, the choice then fell on the Zephyr of 3DFlow, kindly available by the manufacturer, whose results were quite agreeable. The possibility offered by the program of a graphical tracing of polylines on the textured 3D model, has been a considerable advantage. Therefore the results obtained by modeling and surveying of the Palazzolo Acreide theatre have been compared, with the survey of the Syracuse, Taormina and Morgantina theatre performed using 3D laser scanners. First results of the research are matter of the following work.
\end{abstract}

\section{MANUSCRIPT}

\subsection{Historical references}

Reports regarding the foundation of Akrai arrive from Thucydides and date back to 664 B.C. by the people of Syracuse, seventy years after the Syracuse itself foundation.city. The reasons must be sought in the position of the site along the plateau bordered by the river Tellaro and the valley of the river Anapo, whose mouth ends in the port of Syracuse. The fortified city of Akrai in an elevated position, guarded the valley. The political-military purpose was twofold: to limit the Calcidese expansion of the Leontine colony and control the Sicilian populations of the hinterland. Later Akrai also assumed the role of control of the viability that jointed Syracuse with Selinunte. The historical and political events, as well as the splendour and fall, of this city are united with those of the motherland Syracuse. The prestige and wealth achieved in the Hellenistic age are witnessed by the quantity of monuments we admire today (Valastro, 1994). Akray was destroyed in 827 by the Arabs, it remained in oblivion until the discovery in the sixteenth century by the Fazello. Discovery of the theatre belongs to the excavation campaign of 1824 by Baron Gabriele Iudica.

\subsection{The theatre}

Considering its proximity to the city of Syracuse, which at the time was 24 miles ( Lo Faso, 1834-1842), and therefore of its theatre being the largest in Sicily and the western Mediterranean, the presence of the small theatre in the city of Akrai, still testifies to the importance of this settlement. The theatre is attributable to the third century B.C., leaning by a natural slope, with the cavea facing the north of the natural
Anapo's Valley landscape. Dimensions are setting to a diameter of 42,00 mt. in the upper part, and $20.90 \mathrm{mt}$. to the height of the orchestra. The Koilon is also settled according to the Vitruvian rules, it organized into nine wedges (kerkides), separated by eight ladders (Neppi Modona, 1961) and it is defined by a cavea reduced to twelve rows of steps without central diazoma. The lack of paradoi and the perfectly semicircular orchestra, place it among the small theatre buildings in which the passage from the classical model to the Hellenistic typology is better revealed. The scenic plant has a rectangular geometry, without any parascene. In Roman times the theatre underwent some transformations; the area of the orchestra was paved and reduced, the scene was rebuilt and advanced for $2 \mathrm{mt}$., a wooden kiosk was built and a mill was built in the Byzantine period. The most ancient drawing found gives us information relatively to the geometric interpretation as the theatre should have had originally and is due to Francesco Saverio Cavallari (Lo Faso, 1834-1842).

\subsection{The survey}

The photographic acquisition phase included a set of 126 photographs taken with a Canon commercial camera. The atmospheric lighting conditions were those of a sunny day. The photographic parameters used were: ISO sensitivity between 125 and 320, aperture f between 3.2 and 11, shutter speed between $1 / 250$ and $1 / 1250 \mathrm{sec}$. Thus it was possible to guarantee almost uniform chromatic qualities between the various frames. The decision to use a Canon IXUS commercial camera was made to complete an operational analysis of the cameras supplied. 


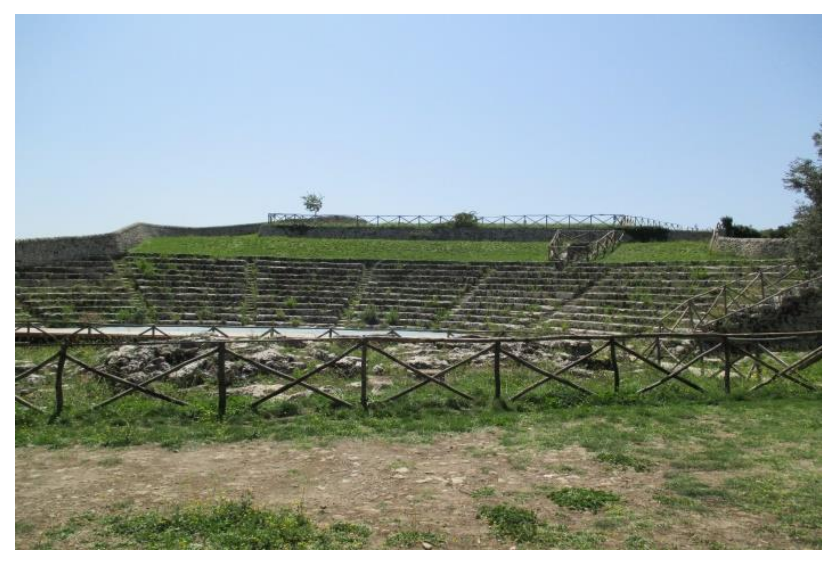

Figure 1 - il Teatro di Palazzolo Acreide

For other photo sets, with the same software, the Canon EOS 1Ds Mark III, Canon EOS 5D full-frame cameras were used. To complete the survey operations measurements were taken, both at the orchestra level and at the top, to be able to scale the model 3D.

\subsection{The processing phase}

The program has five main phases: photographic alignment, the creation of a scattered cloud, the creation of a dense cloud, the processing of meshes, the processing of textured meshesThe phases are in sequence and it is not possible to separately improve a single phase if the previous one had poor results. The most important phases are the creation of the raw cloud and the dense cloud. Several elaborations have been carried out, the first of which in automatic mode with the default parameters to verify the quality of the photographic set. Once the overall quality of the model was established, some parameters were set. Below for brevity only the optimized results are given.

\begin{tabular}{|l|l|l|l|l|l|l|}
\hline$\frac{\mathbf{U}}{\frac{\mathrm{\omega}}{2}}$ & $\begin{array}{l}\text { Photos } \\
\text { aligned }\end{array}$ & $\begin{array}{l}\text { Keypoint } \\
\text { density }\end{array}$ & $\begin{array}{l}\text { Matching } \\
\text { type }\end{array}$ & $\begin{array}{l}\text { Depth } \\
\text { Matching } \\
\text { Phase }\end{array}$ & $\begin{array}{l}\text { Reconstruct } \\
\text { ion engine }\end{array}$ & $\begin{array}{l}\text { Bounding Box } \\
\text { calculation }\end{array}$ \\
\hline 1 & $50 / 50$ & average & fast & average & global & qualified \\
\hline 2 & $88 / 121$ & average & fast & average & global & qualified \\
\hline 3 & $117 / 117$ & high & fast & high & global & qualified \\
\hline 4 & $124 / 126$ & $\begin{array}{l}\text { very } \\
\text { high }\end{array}$ & accurate & full & global & qualified \\
\hline
\end{tabular}

Table 1. varied parameters for the raw cloud

Particular attention was paid to the following parameters: "Keypoint density" and "Depth Matching phase".

The keypoints represent the salient points that are identified on the images, this parameter defines the quantity of salient points that 3DF Zephyr will have to extract for each image loaded. In the very high mode it extracts up to 15,000 keypoints for each image. The depth of the Matching phase controls how many matches between highlights are performed on the images. By setting this parameter to maximum, the possibility of aligning multiple images at the same time increases, at the cost of a longer computing time.

The best results were obtained with the fourth project, where the average reprojection error remained always below 0.90 . So we proceeded on to the elaboration of the dense cloud. Table 2 shows the parameters involved. The raw output type only returns 3D points with real $2 \mathrm{D}$ matches in the images, while the optimized one makes the cloud cleaner and more denser. The number of near photographs defines the number of photographs used to create the depth map.

\begin{tabular}{|l|l|l|l|l|l|l|}
\hline & Type of output & $\begin{array}{l}\text { Numero } \\
\text { camere } \\
\text { vicine }\end{array}$ & Risoluzione & $\begin{array}{l}\text { filtro di } \\
\text { riduzione } \\
\text { rumore }\end{array}$ & $\begin{array}{l}\text { Livello di di } \\
\text { ottimizzaz. }\end{array}$ & $\begin{array}{l}\text { Aggiorna } \\
\text { colori }\end{array}$ \\
\hline 1 & optimized & 4 & $50 \%$ & 15 & average & enabled \\
\hline 2 & raw & 3 & $65 \%$ & 15 & low & enabled \\
\hline 3 & optimized & 3 & $65 \%$ & 15 & average & enabled \\
\hline 4 & optimized & 4 & $70 \%$ & 15 & high & enabled \\
\hline
\end{tabular}

Table 2. changed parameters for the dense cloud

It became clear that by increasing the number from 3 to 4 photographs, better results were obtained. The resolution parameter determines the resolution used for the images. A high resolution keeps more details, but at the same time it can produce "noisy" results if the photos are not of high quality. The noise reduction filter intervenes on the density: low levels of this will produce denser clouds but with the possibility of having noisy areas, while high levels will produce cleaner clouds with fewer end points. This phase is the most challenging in terms of time. The best result was the one related to project 4 . Then we moved on to processing the mesh, and then the textured mesh. The final verification as well as the parameters is done visually by evaluating the quality of definition of the details of the mesh with texture near particular points, such as the edges of the cavea. The presence of spontaneous vegetation in the the stone material has been a problem that could not be addressed.

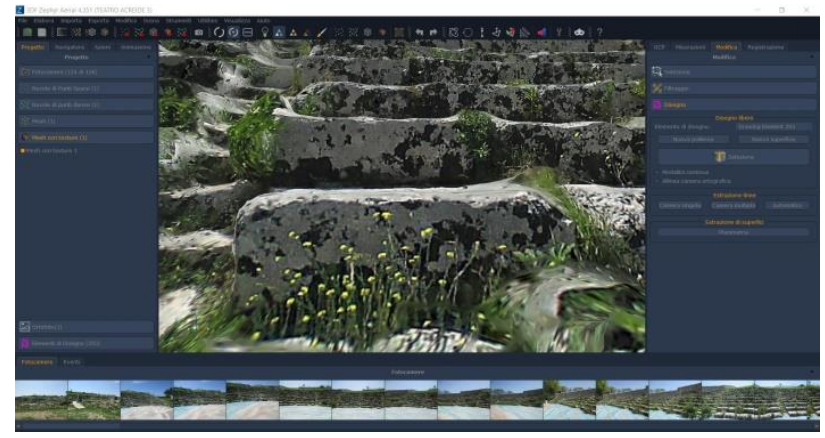

Figure 2 - Palazzolo Acreide theater, detail image of the mesh

\subsection{Model scaling}

The pattern obtained by mesh and texture has been scaled using the control distances. The measurements taken in the survey phase near the edges of the stone segments at the lower level of the cavea were used.

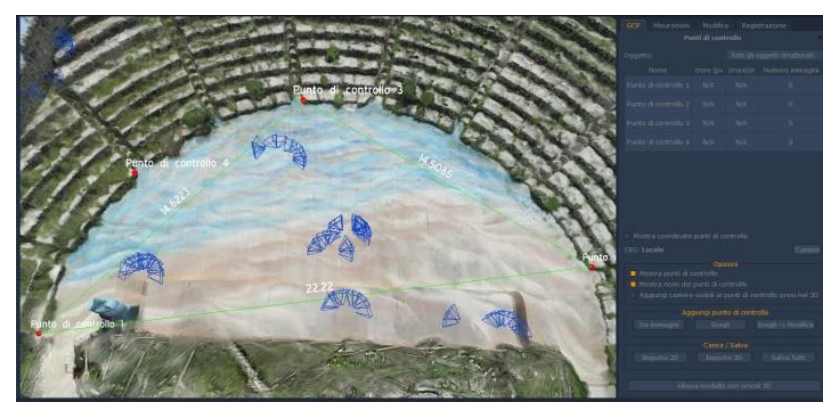

Figure 3 - Palazzolo Acreide theatre, control distances used 
Therefore with the procedure foreseen by the program the control distances between points 1-2, 2-3, 1-3 have been inserted. At each insertion subsequent to the first the program recalculates the previous distances. After verifying the tolerance margin of the three measures, checks were carried out on other known measures.

\subsection{The graphic phase}

The graphic restitution phase required several reflections to establish the most appropriate method of obtaining a vectorial graphic from the three-dimensional model previously elaborated with mesh and texture. An attempt was made to export the textured model to Autocad. The various filters present in the export and import procedures made the textured model lose quality, with a poor definition of the details.

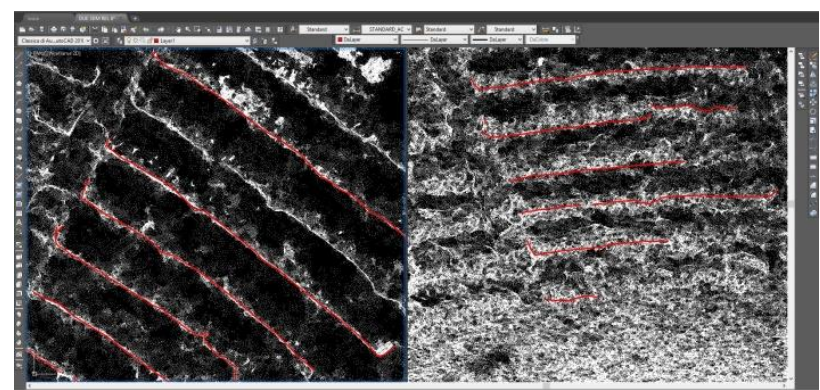

Figure 4 - Tracing of polylines on the cloud in CAD

Then the dense point cloud in dxf format was exported and imported. But the considerable size of the file and the way in which the polylines are traced starting from the points of the cloud, allowed to proceed slowly and with difficulty. So after a few tracking attempts this procedure was aborted.

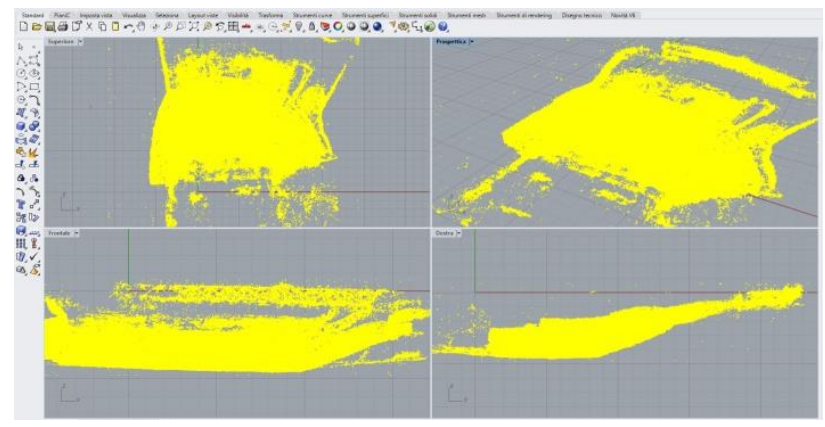

Figure 5 - Rhinoceros: the point cloud in the various projections

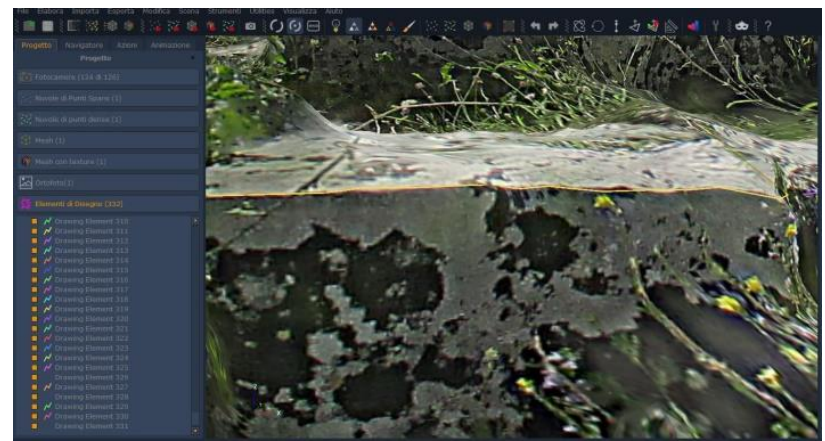

Figura 6 - Zephyr: tracciamento della polilinea sul modello 3D
Subsequently, tests were carried out with Rhinoceros, which provides different file interchange formats, but even in this case the quality of the textured model lost quality and resolution. The possibility of drawing on the dense point cloud provided the same autocad modes. Other attempts have also been made with different software that manage the exchange between structured and unstructured 3D files without obtaining significant advantages. Thus the graphic environment present within Zephyr was taken into consideration. Initially an attempt was made to automatically extract contour lines, but the result did not meet expectations. Subsequently the graphic editor was used which provides manual tracking. The notable advantage is to follow the apparent contour of the objects of the textured model which present a remarkable visual quality.

The ashlars of the cavea wedges have been drawn, following the outline of the edge in a punctual manner, the stairs separating the wedges with the steps in the visible parts, the upper crowning of the cavea. The stone parts infested with vegetation have been left out. A three-dimensional vector model has been obtained, where each polyline representing the edges of the seats is at the real height.

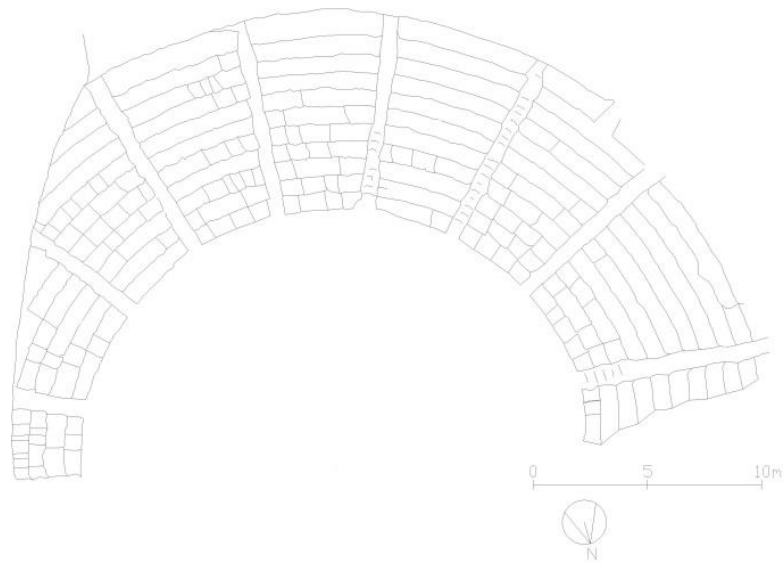

Figure 7 - Palazzolo Acreide, raw draw of the theatre

\subsection{Graphic and compositive interpretation}

Starting from the raw vector graphic of the theatre a modified plan of interpretation of the current state has been elaborated, defining the open lines of the sectors of the cavea. The operation was carried out in compliance with the current conformation, taking into account the incomplete parts of the two end sectors, closing the open lines of the auditorium, interpreting the partial lines of the stone segments of the seats.

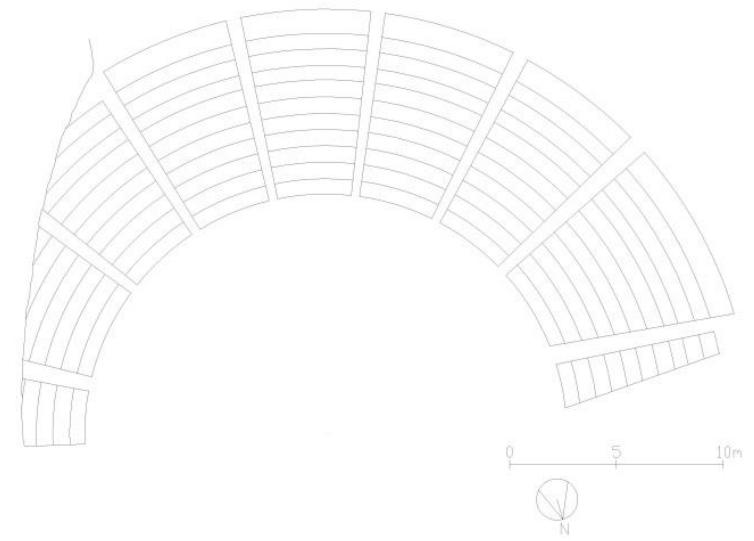

Figure 8 - Palazzolo Acreide, graphic interpretation of theatre 
Subsequently another interpretative plan of the original compositional hypothesis of the theater was elaborated, in which the steps of the stairways, the sectors were regularized and the extremity sectors were reconstructed, it was found that each step is normally $27 \mathrm{~cm}$ high and wide $74 \mathrm{~cm}$ including 34 $\mathrm{cm}$ for the seat and $40 \mathrm{~cm}$ for the tread. The resulting plant was compared overall with that of Cavallari contained in the volume Le Antichità di Sicilia (Lo Faso, 1834-1842). The differences concerned the angular dimensions of the last and the penultimate sector of the ends of each of the two sides. But also in Cavallari's drawings, the penultimate sector of each of the two sides has a wider angular dimension than the central ones. While the last sector of each side is smaller. Furthermore, the penultimate sector facing west has an anomalous dimension compared to its symmetrical one. But we know that at the time of the discovery, on the occasion of the excavation, Baron Judica undertook restoration work and rebuilt the cavea up to the twelfth step. (AA.VV., 2008, anche Regione Siciliana).

All this being said and taking into account that the relief of Cavallari dates back to 1834 , of the instruments of the time and of the period in which the culture of the designers tended to rectify and "to correct" graphically the actual state of ancient monuments (Pagnano, 2001), the inaccuracies of Cavallari are not surprising.

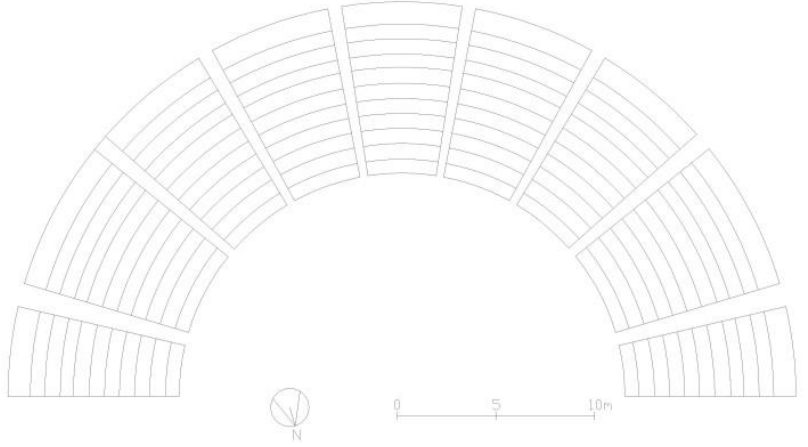

Figure 9 - Palazzolo Acreide, original interpretation

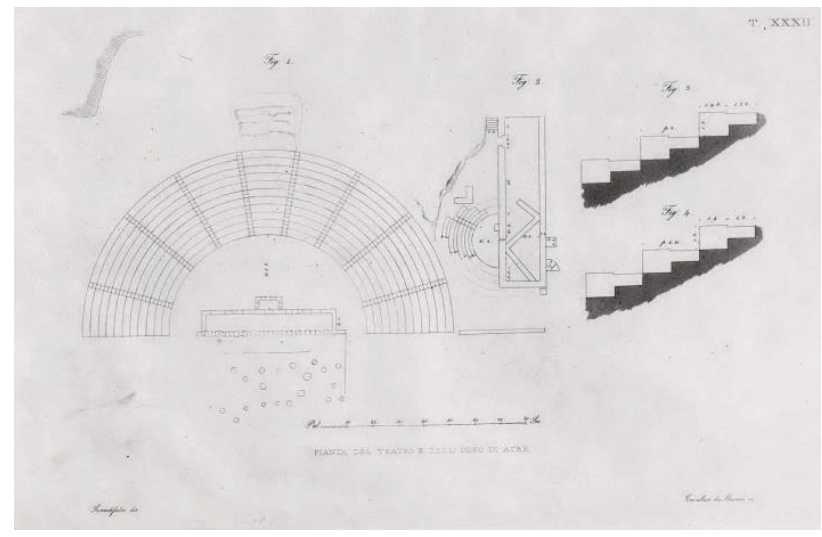

Figure 10 - Palazzolo, engraving by F.S. Cavallari of 1834-1842

\section{COMPARISONS}

\subsection{Geometric comparison with the Theater of Morgantina}

For dimensions and geometry the most appropriate comparison, for the theaters of eastern Sicily, can be made with that of Morgantina, dating back to the mid-third century B.C. For the part received to us it is possible to establish the presence of 6 regular wedges with 16 orders of steps. The orchestra's diameter is about $15 \mathrm{mt}$. and that of the cavea $57.7 \mathrm{mt}$. So the measurements are comparable with those of the theater of Palazzolo Acreide, which even if reconstructed only up to the twelfth step, it was assumed that it reached up to fourteen.

The dimensional and architectural similarities between the two theaters are evident. And considering the hypotheses of historians valid, we know that theaters can be traced back to the same period. Although for both there is no news on the architects, nor on the school, it seems difficult to think that in eastern Sicily there were at the time two different personalities dealing with theaters. Overall, the number of seats is of the same order of magnitude for both equal to around 1000 .

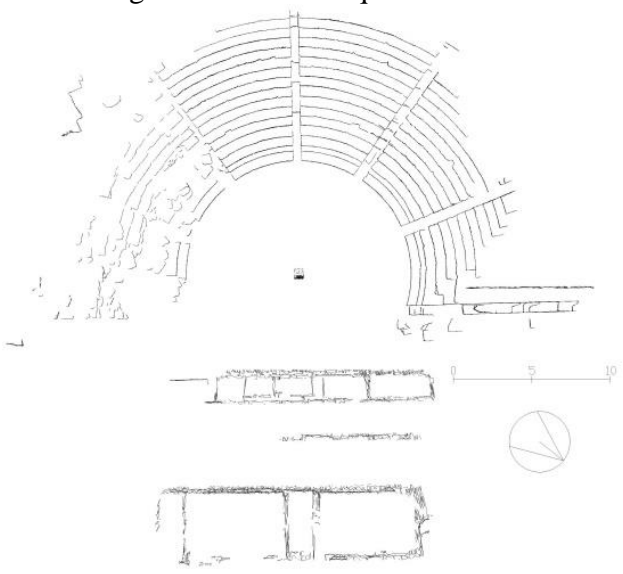

Figure 11 - The theater of Morgantina before the restoration
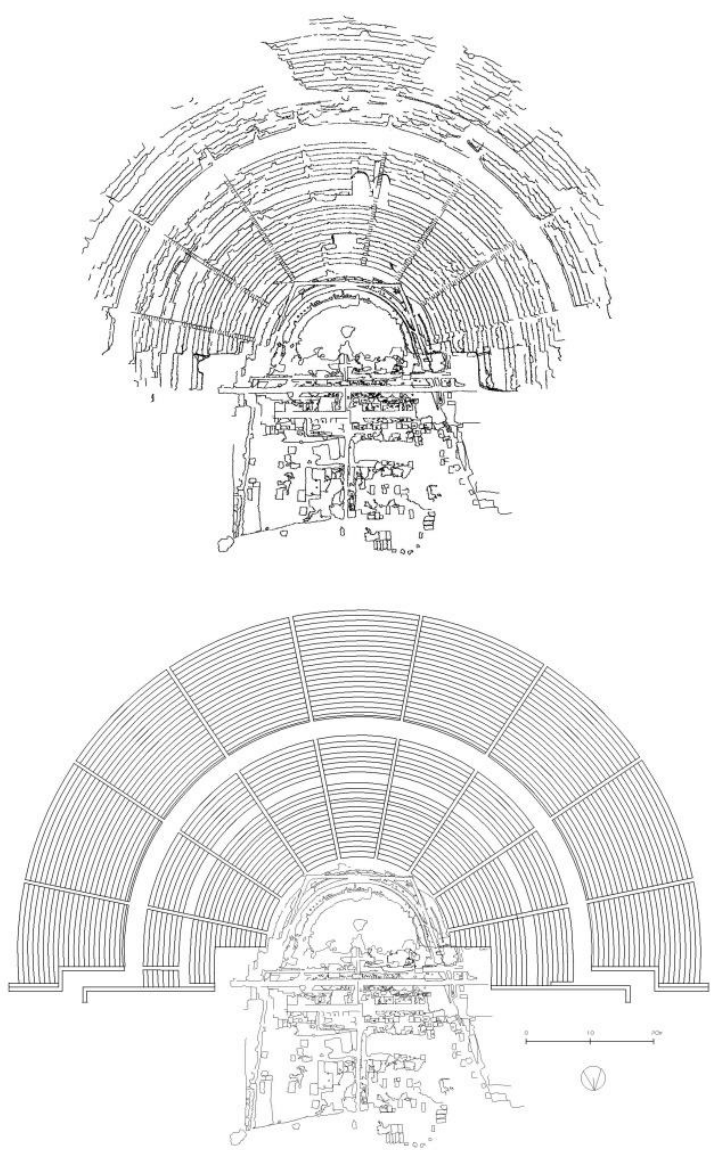

Figure 12 - The Syracuse theatre, restitution and interpretation 


\subsection{Comparison between different 3D survey systems}

In the context of the experience gained for the survey of the theaters, it was decided to do in-depth studies on the quality and validity of the survey methodology Structure from Motion and Dense Matching. The density of cloud points was assessed for theaters in Syracuse, Taormina, Morgantina, surveyed with a 3D laser scanner.

The density of the points was defined as the quantity of points divided by a unitary surface expressed in a square meter of horizontal projection, and was compared with the density of the points of the SFM survey of the theater of Palazzolo Akreide. The Morgantina theater was detected with a 3D laser scanner Rieghel 400, those of Taormina and Siracusa with a Leica HDS 3000 laser scanner. The definition of the matrix of points of these 3D surveys is not the one set a priori on the instrument for each scan, since a survey with a 3D laser scanner is defined by the union of different scans. So the final cloud is given by the union of the individual clouds and presents multiple overlapping areas with an increase in the average density of the points.

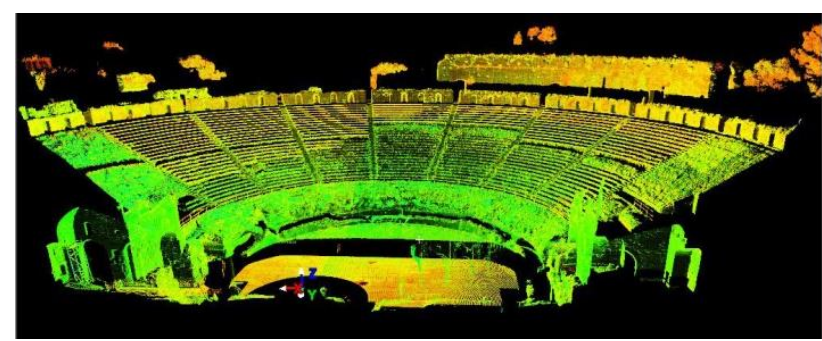

Figura 13 - Taormina, scan of the cavea

The results are shown below in table 3 .

\begin{tabular}{|l|l|l|}
\hline Theater: & survey & point $/ \mathrm{m}^{2}$ \\
\hline Akrai & FSM & 9816 \\
\hline Morgantina & Laser scanner & 1322 \\
\hline Siracusa & Laser scanner & 3334 \\
\hline Taormina & Laser scanner & 4372 \\
\hline
\end{tabular}

Table 3. In comparison the density of the points of the clouds in the different survey.

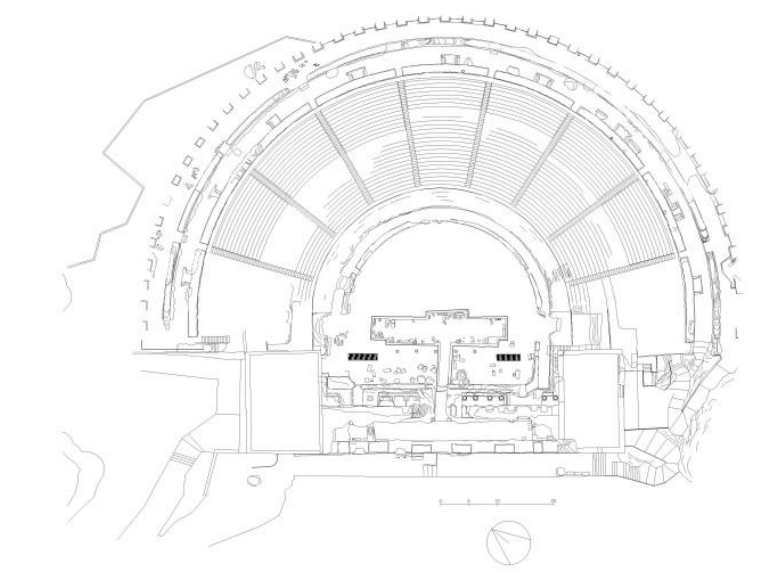

Figura 14 - Taormina theater, geometric interpretation starting from the scan.

The density of the points was calculated near the cavea. Considerations can be drawn from the comparison of the results obtained. The first comparison is between the theater of Akrai and that of Morgantina, the cloud of the theater of Akrai is 7.5 times denser than that of Morgantina detected by laser scanner. Furthermore, the relationship with the two major theaters of Syracuse and Taormina, also detected with a 3D laser scanner, shows that the definition in the cloud with FSM methodology reaches a considerable degree of detail. It must be taken into account that in the SFM method and Dense Matching the density of the points is not defined a priori as in the case of the laser scanner, but depends on many factors related to photographic parameters.

\subsection{Conclusions}

The 3D survey of the Palazzolo Acreide theater was performed using the Structure From Motion and Dense Matching methodology, as an alternative to the 3D laser scanner, completing a broader survey of the Greek and Roman theaters in eastern Sicily. The method certainly more expeditious and at low cost, has proved to be valid for the theater in question. Not having recovered in the literature drawings responding to the current state of degradation, the graphic restitution was performed starting from the textured model. Then dimensional and geometric checks were performed. On the quality of the survey, understood as the density of the point cloud, a comparative comparison was made with the survey performed with laser scanners for the other ancient theaters of eastern Sicily. It is believed that for objects of cultural heritage of this type, this survey system is certainly effective and fast and allows to face the relief in times until unthinkable until yesterday.

Dubayah, R.O., Swatantran, A., Huang, W., Duncanson, L., Tang, H.,Johnson, K., Dunne, J.O., Hurtt, G.C., 2017. CMS: LiDAR-derived Biomass, Canopy Height and Cover, Sonoma County, California, 2013. ORNL DAAC, Oak Ridge, Tennessee, USA. doi.org/10.3334/ORNLDAAC/1523.

\section{REFERENCES}

Valastro S., 1994, La Sicilia dal cielo, Le città antiche, Akrai, Giuseppe Maimone Editore, Catania 1994, ISBN 88-7751-0854, pp. $123-127$

Lo Faso D. Pietrasanta, 1834-1842, Le antichità della Sicilia, esposte ed illustrate per Domenico Lo Faso Pietrasanta, Duca di Serradifalco, Reale Stamperia, vol 4, Palermo 1834-1842, p.159

Neppi Modona A., 1961, Gli Edifici Teatrali Greci e Romani, Leo S. Olschki Editore, Firenze 1961,

Giuseppe Pagnano, 2001, Le Antichità del Regno di Sicilia. I plani di Biscari e Torremuzza per la Regia Custodia. 1779, pp. 86-97, Siracusa, Lombardi Editore 2001. ISBN 978-887 260 0979

AA.VV., 2008, Architetture teatrali antiche siciliane di età antica fase della conoscenza, Collana la Carta del Rischio del Patrimonio Culturale ed Ambientale della Regione Siciliana, Palermo 2008. ISBN 978-88-6164-063-4

\section{Regione Siciliana Assessorato dei Beni Culturali e dell'Identità siciliana.}

http://www.regione.sicilia.it/beniculturali/dirbenicult/database/p age_musei/pagina_musei.asp 